\title{
Corona virus (COVID- 19) and education for all achievement: artificial intelligence and special education needs- achievements and challenges
}

\author{
Yahya Muhammed Bah ${ }^{1}$, Myrtati Dyah Artaria ${ }^{1^{*}}$ \\ ${ }^{1}$ Department of Sociology, Faculty of Social and Political Sciences, Universitas Airlangga, \\ Surabaya, Indonesia \\ ${ }^{*}$ Corresponding author, $\equiv$ e-mail: myrtati.artaria@fisip.unair.ac.id
}

\begin{abstract}
The shortage of well-trained teachers especially in special education is a serious problem worldwide. To attain education for all as enshrined in the Sustainable Development Goals (SDGs), there is urgent need for robot ways of solving this problem with grave consequences for the future of children with disabilities and special education needs. Thus, education delivery methods like other services need to be innovative. The purpose of this studi is to examine the achievements and challenges in the application of AI for teaching children with special education needs. This research used the literature review method. The result of this study shows that AI has the power to enhance learning for children with special needs while curbing some of the problems such children are encountering in accessing quality and relevant education. In conclusion the findings revealed some significant achievements and the possibilities of more if the appropriate technologies are applied consistently with the right environment both in schools and homes.
\end{abstract}

Keywords: Education for all, children with disabilities, artificial intelligence, special education needs, achievements, challenges, COVID-19

How to Cite: Bah, Y., \& Artaria, M. (2020). Corona virus (COVID- 19) and education for all achievement: artificial intelligence and special education needs- achievements and challenges. COUNS-EDU: The International Journal of Counseling and Education, 5(2), 64-70. DOI: $10.23916 / 0020200528630$

\section{Introduction}

Teachers play very critical roles in the socio-economic and political development of societies in addition to their principal duties imparting knowledge, creating classroom environment, role modeling, mentoring and nurturing, listening and looking out signs of discomfort, controlling, prompting, being a resource, assessor, organizer, participant, tutor, etc. Guyana Ministry of Education (n.d.).

In spite of these roles teaching is playing, there is great shortage of well trained teachers especially in special education; and is a serious problem worldwide. To attain education for all as enshrined in the Sustainable Development Goals (SDGs), there is urgent need for robot ways of solving this problem with grave consequences for the future of children with disabilities and special education needs. Thus, education delivery methods like other services need to be innovative. Information Communication Technologies (ICTs) have commenced to render such opportunities even in the delivery of special education needs through the Artificial Intelligence (AI) methods, Assistive Technologies (ATs) inclusive.

AI is differently defined by various authors. However, critical in most definitions is that it is an activity devoted to making machines intelligent with the ultimate objective of making it function 
appropriately and with foresight in its vicinity. Therefore, it is a computer science meant to solve intellectual problems that are mostly associated with human intelligence like learning, problem-solving, pattern recognition, etc. similarly, it is critical in executing functions that require human intelligence namely; visual perception, speech recognition, decision-making, translation between languages, etc. Thus, it is purely computer systems that try to imitate human behavior, paving the way for personalized, adaptive learning, enabling advising systems that enhance students' experience. Similarly, it is being used for student assessment, enhancing the experience of students with disabilities, advancing the capabilities of learning analytics, etc. However, its application raises ethical, moral and privacy concerns. Its implementation in higher learning institutions is challenging though transforming other areas of academic life, too as it is highly associated with the advancement of higher education, Northonlinelearning (n.d.).

AIs including Assistive Technologies (ATs) to be productive both in the classroom and at home, the right tool must be selected, Adebisi R.O. et al., (2015). Assistive technology has the power to improve the life and living conditions of children with disabilities and above all eradicate some of the learning barriers.

Learning disabilities though cannot be treated and children grow up with it, with the right technologies, their learning abilities can be significantly improved (Raskind, 2000) as cited in, Adebisi R.O. et al., (2015). Assistive technologies are useful to children with disabilities in numerous ways such enhancement of the acquisition of basic knowledge and skills. Thus, they are educational tool just like pen and pencils for students without disabilities as they use to access all materials that can make them competitive in class and outside the classroom. All tools may not be necessarily user friendly and as such the type of tool to be used must be well determined and applied vis-à-vis the child learning needs and critically vital, they must facilitate both communication needs and changing environments; and the use must be continuous productivity, Adebisi R.O. et al., (2015). Assistive technology include among others, tape recorders, remote control, smart glasses or magnifier, cognitive hearing aids, parkinson's disease balancing application, lock-in syndrome, sign language, etc. (Quenneville, 2002).

AI including ATs is particularly useful for children who have difficulties in listening, mathematics, organization and memory, reading; and writing skills, Adebisi R.O. et al., (2015). In selecting the right ATs for children with learning disabilities, it is critical that the followings are put into serious consideration: the child's specific difficulties, establishing the child strengthens, involving the child in the selection processes, choosing the right ATs based on the child strengths and weaknesses, determining the specific location were the tool is to be used, selecting ATs that work well jointly, selecting ATs that are user friendly; and work well, Adebisi R.O. et al., (2015).

AI can do all that a human teacher can do including content creation, providing inspiration for learning, attending to difficult questions; and social interaction that are critical for effective learning (Johnson J. 2003).

However, a preliminary but intensive literature reviewed has revealed that there are no well documented Artificial Intelligence and Special Education Needs (SEN) delivery. Furthermore, this lack of systematic documentation beyond reasonable doubts has posed a great challenge for academics, human rights advocates, government institutions, NGOs; and social workers to both develop strategies and mobilize resources in supporting children with learning disabilities to access quality and relevant education. Thus, this research is meant to address this gap in order to contribute to the crusade; education for all.

The fundamental rationale for the literature review is to examine the present scale and degree of the application of Artificial Intelligence in the delivery of Special Education Needs (SEN), share knowledge to spark and inspire a process that will usher rapid growth from all directions in ensuring that AI and ATs are promoted and supported for children with learning difficulties to access affordable, quality and relevant education like all other children.

\section{Method}

A systematic review of the literatures using information collected from different sources was actuated. Google Search Engine was used to search for these articles. During the search numeration combinations of words and phrases were used to ensure articles reflect the most recent knowledge and 
scholarly publications. The systematic searches beget varied and voluminous articles which had to be sieved not only to meet the inclusion and exclusion criteria but to ensure the fundamental objectives of the study are wrangled.

Therefore, only peer-reviewed scholarly publications published after 2000 were selected except extracts perceived to be of basal mileage to the study. However, articles published by staunch international organizations known to have been working in special education needs delivery for years and has produced indefatigable knowledge in the area were stealthily appraised.

\section{Inclusion and exclusion procedures}

The underneath procedures were followed in articles inclusion. That is, only: 1) Peer-reviewed scholarly articles; 2) Peer-reviewed scholarly articles on AI and SEN delivery; 3) Peer-reviewed scholarly articles published from 2000 to 2020; 3) Articles on international or regional perspectives on AI and SEN; 4) Articles on AI and SEN published by internationals organizations with years of meritorious experience.

To exclude some articles from the review, the below captioned criteria were applied. That is: 1) Non-peer reviewed articles; 2) Articles published before 2000 unless critical and impactful; 3) Media generated articles including newspapers; 4) Articles not published in English language.

In spite of the fact that both qualitative and quantitative articles were trawled, only twenty seven (27) articles were qualified for reviewed which is largely due to a dearth of data. In essence, only peerreviewed articles and publications by international organizations considered being trustworthy because they occasioned standard, ethical and robust studies were reviewed.

\section{Results and Discussions}

As can be observed above, the literature reviewed has disinterred a variety of AI and ATs in application to facilitate children with learning disorders to access affordable, quality and relevant education like all other children. To discuss these pernicious technologies or methods, they are codified into: imparting knowledge through addressing written language, reading, listening, memory; and solving arithmetic problems), creating classroom environment, role modeling, mentoring and nurturing, listening and looking out signs of discomfort, controlling, prompting, being a resource, assessor, organizer, participant; and tutor some of the fundamental roles of teachers.

\section{Imparting knowledge}

One of the fundamental roles of a teacher is to impart knowledge in student based on a designed and approved programmes. To impart knowledge, teachers apply different strategies ranging from one-on-one to group work sometimes with the support of simple teaching aids or more complex ones depending on the topics and the students being lectured, Keiler L.S. (2018). In case of children with learning difficulties different Assistive Technologies (ATs) including Artificial Intelligence have been applied as validated: ATs generally are helpful in ensuring that children with disabilities access education in several ways namely; in developing independence in academic and employment duties, participation in classroom debates and discussions, reaching out to peers, role models and teachers, self-advocacy, making the best use of the available educational opportunities, independence in living and learning with minimum support, performing side-by-side with fellows, mastering academic tasks, comprehending educational assignments with ease; and participation in communities' development programmes and recreational activities, Burgstahler, (2003). AI supports the creation of quality education, effective studies, study plan, adopt educational content, online student profile which can be used to assign a student a personal teacher. Thus, it can boost productivity both in the classroom and outside and above all, such portfolios delivered lessons and courses can be of great help to employers, Chassignola M. et al. (2018). AI is used in many educational sectors viz. content development, teaching methodologies, student assessment; and communication between teacher and students, Chassignola M. et al. (2018).

Similarly, in written language, ATs support students through spelling checker, proofreading or grammar checker, speech synthesizer, speech recognition, etc. Adebisi R.O. et al., (2015). Through variable speech control, optical character recognition, speech synthesis, tape recorder, Microsoft word, etc. ATs have increased students' independence in reading, Adebisi R.O. et al., (2015). 
In the same vein, in mathematics ATs are supporting students with learning disabilities through talking calculators, electronic mathematic worksheet, etc. So too it is, in listening as ATs are helping students with learning difficult through FM listening systems, tape recorders, etc. Adebisi R.O. et al., (2015). In memorizing and organizing, ATs aid students with learning disabilities via personal data manager, free-form databases, prewriting organizers, etc. Adebisi R.O. et al., (2015).

In addition, AI has led to revelation and enhancement of many individual children's specific abilities, consolidation of research and education; and enhances optimal productivity for both learners and teachers, Pomsta K.P. et al. (2018). Thus, AI is critical in enhancing the formulation and implementation of culturally sensitive education while making the creation and production of knowledge much easier and affordable to support children with special needs, Almokaramah M. (2013).

\section{Creating learning/classroom environment}

For effective learning to take place, the creation of conducive environment is critical. With such an environment, the children are at ease and their brains relaxed, ready to absorb, participate and even sometimes challenge what is being delivered, Graetz K.A. (n.d.). The creation of such environment has witnessed the application of numerous strategies including computer generated support systems for effective learning, concurring with: AI in education is changing many things including conventional thinking, teaching, learning, traditional models of schools and classrooms, ability to tailor learning to the very needs of various students in light of their cognitive, emotional, instructional dimension. Similarly, it facilitates learning environment like content management, liberate teachers from bureaucracy management to focus on children's academic progress, etc. Mohammed P.S. et al. (2019). AI in addition to being very effective in e-learning, it is suitable for one-on-one learning, collecting data on users' interests and responding promptly without pressure and interfering with users' privacy, Almokaramah M. (2013). ATs promote sense of belonging and interactive participation, rate of assignment completion; and motivation for children with learning difficulties (Bryant \& Bryant, 1998).

Similarly, AI while opening new opportunities in teaching and learning for the attainment of education for all, it is both challenging and fostering lifelong learning methodologies that can preserve the integrity of core values and the purpose of education, Popenici S. et al. (2017). Full-fledged robot teachers can be helpful in many areas such as being classroom assistant, student peer, building affective relationship with students, classroom management; and above all, performing high level cognitive action (Manyika et al., 2017) as quoted in Bosede I.E. et al., (2017). Thus, AI has demonstrated that effective and individually articulated approaches can be attained by applying AI techniques and intelligent learning environment, Mohammed P.S. et al. (2019).

\section{Mentoring, nurturing and security}

For students to develop to their fullest capacities, mentoring is fundamental. Teachers are generally known to be great mentors because they listen, encourage and motive students to both take the ownership of their education while building their confidence to face future challenges. With such, students are stirred to perform to their best with dedication and optimal seriousness, Eleyan et al. (2011). To create such atmosphere and aspiration in students, especially those with learning disabilities, technologies have made some impacts as substantiated by: AI as computer generated tool performs different functions including the stimulation of intelligence and problem solving skills. Furthermore, it is recognized as the most valuable application in the delivery of special education needs as it among others can diagnose disabilities and assigned appropriate interventions, facilitate children's interaction with their environment to escalate learning and quality of daily life, Drigas et al. (2012). AI is critical in special education as it doesn't injure anyone or through inaction, permit any person to be harmed. It always obeys orders given by a human being unless the order is harmful. It always ensures its welfare is highly protected as long as it doesn't harm a human being, Tucker E.A. (2016).

\section{Listening and looking out signs of discomfort/diagnose}

For any effective learning to materialize the students must be physically, mentally and psychological secured. Therefore, the security of children is a cardinal role in knowledge imparting. Teachers as protectors have been executing this role through different methods including observing behaviors, physical appearance, emotional stabilities, listening to concerns expressed by pupils, Valiente, C. et al., (2012). The teaching fraternity like others has enjoyed support of modern technologies in this regards as asserted: socially assistive robots (SARs) has assisted human development in many respects including physical 
assistance, therapy delivery, building behavioral skills, treatment and diagnosis of disorders; and analysis of human behaviors, Dickstein-Fischer L.A. (2017). AI has the capacity to diagnosis a student to enable authorities to design appropriate intervention methods to support him or her. Thus, AI doesn't only benefit students with special needs but even those working with them including parents and caregivers, Drigas et al., (2013).

AI has significantly contributed in diagnosing, evaluation, pedagogical psychology profiles, solutions, educational activities, strategies, skills; and tools that are fundamental in support of students with special needs, Ilkka T. (2018).

Similarly, AI has made assessment, identification of teaching and learning gaps easier and faster. However, it is not fault freed thus, occasionally; it needs human mentors, Chassignola M. et al. (2018). AIs have equally played significant roles in sports, self-driving cars, and diagnosis in healthcare facilities; and they have supported sexual partners in the social realm (Brandy, 2006) as cited in Bosede I.E. et al., (2017).

\section{Teaching and learning resources}

To effectively impart knowledge, the need for teaching and materials cannot be overemphasized. Teachers in their quest to deliver quality and relevant education have applied various strategies to acquire the needed resources, Kapur R. (2019). The unprecedented advancement in science and technology has significantly impacted their efforts as elucidated: AI facilitates the acquisition of interactive aid in solving problems, new domain knowledge, diagnosing disabilities, teacher easily getting psycho pedagogical evaluation of pupils who has learning disabilities; and importantly it provides a tool box for teachers to use in supporting children with special education needs, Almokaramah M. (2013). AI technology creates lot of opportunities for development of huge open online libraries, Chassignola M. et al. (2018).

\section{Barrier removal and interventions}

In the transfer of knowledge and skills, especially in special education, there has been lot of barriers soliciting immediate interventions to ensure children with learning disabilities enjoy access to quality and relevant education, a fundamental human to be enjoyed by all, Wright C.M. (2016). To remove these barriers and accord right interventions, educational institutional including teachers and philanthropists have employed different methodlogies encompassing AI as reaffirmed: AI provides data on accuracy, consistency, reciprocity; and immediacy that are fundamental in the interventions in support of children with learning disabilities in measuring their progress, Dickstein-Fischer L.A. (2017). Thus, it makes therapist affordable, accessible; and reduces the administrative burden on therapist, Dickstein-Fischer L.A. (2017). AI methods have significantly improved the quality of life of students with special needs education as it has successfully removed some barriers to learning. It integrates the freedom of action of the student and furthermore enhances the attainment of his or her personal goals, Drigas et al., (2013).

\section{Profit making and other uses}

Human being, in his quest to gather wealth with moderate expenses has always been exploring different avenues. In the area of alternative labor, lots of successes have been registered more especially with the advancement of science and technology, Emst E. et al., (2019). To safe cost while boosting productive, AI and ATs have made huge impacts as attested to: the growth of AI can be associated with many factors such as economic benefits of tireless labor, fueling automation since industrial revolution, the desire for teachers who do not pay regards to job dissatisfaction, recognition or remuneration, those with no need for autonomy, leaves, rests, and more especially those who are not limited by natural affective demands such as changes in moods, anger; and tiredness, Bosede I.E. et al., (2017). Robots although originally thought not to be capable of doing many things, today they are human co-workers in factories, as companion to students in class; and as support for students with disabilities, critically sick and elderly persons, National Academy of Sciences (2019). The economic rewards of tireless labor inspires the need for instructors who are unlimited by natural human demands, highlighting consideration for affordances of robotics and $\mathrm{AI}$ in education as currently happening in many aspects of human life, Bosede I.E. et al., (2017).

It reduces the workload and stress for teachers in the classroom while facilitating supportive education and inclusive, virtual learning and above all, lessen frustration, increase motivation, promote peer acceptance; and increase productivity both in class and at home, Adebisi R.O. et al., (2015). 
Similarly, AI is profitable for both companies and the market in their functions for it means less human resources and less salaries payments, Chassignola M. et al. (2018). In addition to facilitating teaching and learning, AI is daily applied in cities, campuses around the world, internet search engines, smartphone features and applications, public transport; and household appliances, Popenici S. et al. (2017).

\section{Limitations and challenges}

Broadly, the application of science and technology in services delivery is not without limitations more especially in the least developed nations, Pholphirul P. et al., (2014). Thus, the use of AI and ATs in special education is no exception as affirmed:

In using the AI and ATs there are lot of challenges face both by the students and institutions that support the children viz. lack of ICT specialists, limited flexibility, limited disabilities friendly ATs especially in the developing nations, lack of government investment in support of ATs, public attitudes towards disabilities and children with disabilities more especially learning disabilities, lack of disabilities laws and policies and poor implementations where they exist; and lack of financial support particularly in third world countries, Adebisi R.O. et al., (2015). AI in spite of having the power to structurally change educational institutions both administratively, teaching wise and learning, it has the potential of posing some challenges to the sector namely; detecting irony, sarcasm, repetitive use of punctuation marks, use of capital letters or key phrases, Popenici S. et al. (2017). In developing countries its application is hindered by sparse and incomplete data, inadequate resources; and lack of technical skills, Mohammed P.S. et al. (2019).

ATs cannot eradicate learning difficulties however; learning to strengthen the technologies will improve the life and living conditions of students' with learning difficulties, Adebisi R.O. et al., (2015). Robotic personalities though capable of supporting students especially those with disabilities, it cannot be a perfect replacement for classroom teachers, Bosede I.E. et al., (2017). While AI is enhancing teaching and learning and above all, augmenting teachers' productivity, it is not yet ready to replace teachers, Popenici S. et al. (2017). AI though a beautiful replacement of human being in some areas, they cannot inspire humans, develop social skills; and emotional intelligence needed by teachers, Bosede I.E. et al., (2017).

AI effectiveness in education requires regulation to ensure they serve the purpose of their introduction in the system, Mohammed P.S. et al. (2019). AI needs to be formalized applying neutral, adequate developed techniques to ensure the cultural factors that regulate presentation, delivery and customization of content and system behavior, Mohammed P.S. et al. (2019).

\section{Conclusion}

In conclusion the findings revealed some significant achievements and the possibilities of more if the appropriate technologies are applied consistently with the right environment both in schools and homs. Notwithstanding, AI is not limitations immune.

\section{References}

Adebisi R.O. et al., (2015). Using Assistive Technology in Teaching Children with Learning Disabilities in the 21st Century. Available at: https://files.eric.ed.gov/fulltext/EJ1078825.pdf

Almokaramah M. et al. (2013). Diagnosing Learning Disabilities in a Special Education by an Intelligent Agent Based System.

Bosede I.E. et al., (2017). Why not Robot Teachers: Artificial Intelligence for Addressing Teacher Shortage.

Bryant \& Bryant (1998). Using Assistive Technology to Enhance the Skills of Students with Learning Disabilities. Available at: https://journals.sagepub.com/doi/abs/10.1177/105345129803400109

Burgstahler( 2003). The Role of Technology in Preparing Youth with Disabilities for Postsecondary Education and Employment. 
Chassignola M. et al. (2018). Artificial Intelligence trends in education: a narrative overview. Available at: https://pdf.sciencedirectassets.com/280203/1-s2.0-S1877050918X00131/1-s2.0S1877050918315382/main.pdf?X-Amz-Security-

Dickstein-Fischer L.A. et al., (2017). Socially assistive robots: current status and future prospects for autism interventions. Available at: https://www.dovepress.com/socially-assistive-robots-currentstatus-and-future-prospects-for-auti-peer-reviewed-fulltext-article-IEH\#

Drigas A. et al. (2012). Artificial intelligence in special education: A decade review. International Journal of Engineering Education.

Drigas A. et al., (2013). A Review on Artificial Intelligence in Special Education. Communications in Computer and Information Science. 278. 385-391. 10.1007/978-3-642-35879-1_46.

Eleyan et al. (2011). Coaching, Tutoring and Mentoring in the Higher Education as a solution to retain students in their major and help them achieve success.

Emst E. et al., (2019). Economics of Artificial Intelligence: Implications for the Future of Work.

Graetz K.A. (n.d.). Chapter 6. The Psychology of Learning Environments. Available at: https://www.educause.edu/research-and-publications/books/learning-spaces/chapter-6-psychologylearning-environments

Guyana Ministry of Education (n.d.). Roles of a Techer in the Classroom. Available at: https://www.education.gov.gy/web/index.php/teachers/tips-for-teaching/item/1603-roles-of-ateacher-in-the-classroom

Ilkka T. (2018). The Impact of Artificial Intelligence on Learning, Teaching, and Education: Policies for the Future. 10.2760/12297.

Johnson J. (2003). Children, robotics, and education. Artificial Life and Robotics. 7. 16-21. $10.1007 / \mathrm{BF} 02480880$.

Kapur R. (2019). Development of Teaching-Learning Materials. Available at: https://www.researchgate.net/publication/334083571_Development_of_TeachingLearning_Materials

Keiler L.S. (2018). Teachers' roles and identities in student-centered classrooms. https://doi.org/10.1186/s40594-018-0131-6. Available at:

https://stemeducationjournal.springeropen.com/articles/10.1186/s40594-018-0131-6

Mohammed P.S. et al. (n.d.). Towards Inclusive Education in the Age of Artificial Intelligence: Perspectives, Challenges, and Opportunities.

National Academy of Sciences (2019). Artificial Intelligence in Health Care: The Hope, the Hype, the Promise, the Peril

Pholphirul P. et al., (2014). IT investment and constraints in developing countries: Evidence from Thai manufacturers. Available at: https://journals.sagepub.com/doi/10.1177/0266666914535616

Pomsta K. P. et al., (2018). Blending Human and Artificial Intelligence to Support Autistic Children's Social Communication Skills. Available at: https://dl.acm.org/doi/10.1145/3271484

Popenici S. et al. (2017). Exploring the impact of artificial intelligence on teaching and learning in higher education. Research and practice in technology enhanced learning, 12(1), 22. https://doi.org/10.1186/s41039-017-0062-8

Quenneville, J. (2002). Tech Tools for Students with Learning Disabilities: Infusion into Inclusive Classrooms. Preventing School Failure. 45. 167-170. 10.1080/10459880109603332. Available at: https://www.researchgate.net/publication/247524461_Tech_Tools_for_Students_with_Learning_Di sabilities_Infusion_into_Inclusive_Classrooms

Tucker E.A. (2016). Artificial Intelligence and Disability: An Academic Study of AI Use in The Classroom for Students with Disabilities. Available at: https://www.elijahatucker.me/projects/Tucker_Elijah_Thesis.pdf

Valiente, C. et al., (2012). Linking Students' Emotions and Academic Achievement: When and Why Emotions Matter. https://www.ncbi.nlm.nih.gov/pmc/articles/PMC3482624/

Wright C.M. (2016). Teacher Perceived Barriers to Inclusive Instructional Delivery Approaches. 